\title{
Evaluation of echocardiography on the neonatal unit
}

\author{
S Moss, D J Kitchiner, C W Yoxall, N V Subhedar
}

Arch Dis Child Fetal Neonatal Ed 2003;88:F287-F291

See end of article for authors' affiliations

Correspondence to:

Dr Subhedar, Neonatal

Intensive Care Unit,

Liverpool Women's

Hospital, Crown Street,

Liverpool L8 7SS, UK

nvsubhedar_lwh@yahoo.com

Accepted 30 August 2002

\begin{abstract}
Background: Echocardiography is an investigation that is being used increasingly on the neonatal unit. There is some controversy as to whether this service can be provided safely and effectively by neonatologists or whether it should only be performed by paediatric cardiologists.

Aims: To describe (a) the indications for an echocardiogram, $(b)$ the yield and range of positive findings, $(c)$ the resulting changes in clinical management, and $(d)$ the reliability of echocardiography in the hands of neonatologists when it is performed on the neonatal unit.

Methods: Information about all echocardiograms performed on the neonatal unit was collected prospectively. Indications for performing echocardiography, echocardiographic findings, and any resulting changes in clinical management were determined. The concordance of findings in infants who underwent echocardiograms performed by both a neonatologist and a paediatric cardiologist was described.

Results: A total of 157 echocardiograms were performed in 82 infants. Echocardiography identified 44 infants with a structural cardiac abnormality and a further 17 infants with a trivial abnormality. In addition, 13 babies were found to have an important functional abnormality. Echocardiography prompted a specific change in clinical management in $64(78 \%)$ babies. In 31 of the 38 infants who had paired scans performed, there was complete concordance between the two examinations. No infants had scans that were completely different. Some discrepancy was identified in seven infants, but this did not prevent appropriate immediate clinical management.

Conclusions: Echocardiography on the neonatal unit has a high yield for the diagnosis of structural and functional cardiac abnormalities, often results in a change in clinical management, and can be a reliable tool in the hands of neonatologists.
\end{abstract}

$\mathrm{T}$ wo dimensional and Doppler echocardiography is being used increasingly in neonatal units to investigate neonatal cardiac structure and function. Many neonatal units in the United Kingdom do not have ready access to paediatric cardiology services, and this has resulted in neonatologists often taking on this role. ${ }^{12}$ There is some controversy as to whether this service can be provided safely and effectively by neonatologists with an interest in echocardiography, or whether it should only be performed by paediatric cardiologists. $^{3-7}$ Despite this continuing debate, there is little published information prospectively evaluating the use of echocardiography in the neonatal unit in an objective and systematic way. ${ }^{8}$ At the same time a number of textbooks, teaching aids, and practical echocardiography courses are becoming available for neonatologists looking to develop an interest in neonatal echocardiography. ${ }^{10}$

The purpose of this study was to describe the indications for echocardiography, the yield of positive findings, and the resulting changes in clinical management when echocardiography is performed on the neonatal unit. We also aimed to evaluate the reliability of echocardiography in the hands of neonatologists.

\section{METHODS}

We conducted a prospective observational study based at a UK regional referral neonatal centre. Over eight months, the following information was collected whenever an echocardiogram was performed on the neonatal unit: basic patient details, indication for performing echocardiogram, whether the echocardiogram was performed by a neonatologist or paediatric cardiologist, findings on echocardiography, and any changes in clinical management following the scan.

Liverpool Women's Hospital has a stand alone regional referral centre for neonatal intensive care without an on site paediatric cardiology service. A single paediatric cardiologist (DK) sees infants once a week for non-urgent review of suspected or proven cardiac disorders. At all other times, echocardiography is either performed by one of two neonatologists (CWY and NVS) or, in an urgent situation, by an on call paediatric cardiologist.

Indications for performing echocardiography were broadly categorised as follows: asymptomatic murmur; cardiorespiratory symptoms (cyanosis, shock, hypoxaemic respiratory failure, hypotension, and arrhythmia) with or without a murmur; antenatal diagnosis of cardiac defect; family history of cardiac defect; and non-cardiac congenital malformation. Two dimensional and colour Doppler echocardiographic examinations were performed using a Toshiba Corevision Pro system with a $7 \mathrm{MHz}$ multifrequency imaging transducer combined with a 5 MHz Doppler transducer.

Infants found to have a completely normal echocardiogram, or a "trivial" structural abnormality such as patent foramen ovale, haemodynamically insignificant persistent ductus arteriosus (PDA), or mild "physiological" left pulmonary artery stenosis were classified as having no structural cardiac abnormality. ${ }^{11}$ Persistent pulmonary hypertension of the newborn was diagnosed in the presence of normal cardiac anatomy with Doppler echocardiographic evidence of a right to left extrapulmonary shunt at atrial or ductal level. ${ }^{12}$ Infants with poor left ventricular contractility (fractional shortening $<30 \%$ ) or low left ventricular output ( $<150 \mathrm{ml} / \mathrm{kg} / \mathrm{min}$ ) were classified as having left ventricular dysfunction. ${ }^{13}$

In infants who had paired scans (performed by both specialists at different times), the concordance between the two scans was evaluated. Two observers (DK and NVS) independently reviewed the echocardiography reports to grade the degree of concordance present. An arbitrary system was chosen: no concordance, moderate concordance, and complete concordance. In instances where no/moderate 
Table 1 Details of echocardiograms performed by both neonatologist and cardiologist

\begin{tabular}{|c|c|c|}
\hline & Paired scans & Single scan \\
\hline Number of infants scanned & 38 & 44 \\
\hline Total number of scans & 109 & 48 \\
\hline Neonatologist & 53 & 24 \\
\hline Cardiologist & 56 & 24 \\
\hline Scans/infant & $2(2-3)^{* *}$ & $1(1-1)$ \\
\hline Birth weight (g) & $1770(1018-3232)$ & $1568(1051-2958)$ \\
\hline Gestation (weeks) & $34(27-39)$ & $32(27-38)$ \\
\hline Age at first scan (days) & $2(1-12)$ & $3(1-29)$ \\
\hline \multicolumn{3}{|l|}{ Clinical indication } \\
\hline Asymptomatic murmur & 13 & 16 \\
\hline Cardiorespiratory symptoms (with murmur) & 7 & 5 \\
\hline Cardiorespiratory symptoms (without murmur) & 9 & 10 \\
\hline Antenatal diagnosis of cardiac defect & 5 & 5 \\
\hline Family history of cardiac defect & 4 & 8 \\
\hline Non-cardiac congenital malformation & 0 & 0 \\
\hline \multicolumn{3}{|l|}{ Echocardiographic findings } \\
\hline Normal structure & $3^{*}$ & 22 \\
\hline Congenital structural abnormality & $20 *$ & 10 \\
\hline Haemodynamically significant PDA & 11 * & 3 \\
\hline Persistent pulmonary hypertension of the newborn & 3 & 6 \\
\hline Left ventricular dysfunction & 1 & 3 \\
\hline $\begin{array}{l}\text { Values are expressed as number, or median (interqu } \\
{ }^{*} p<0.05,{ }^{* *} p<0.001 \text { compared with infants having } \\
\text { PDA, Persistent ductus arteriosus. }\end{array}$ & $\begin{array}{l}\text { range). } \\
\text { ngle scan. }\end{array}$ & \\
\hline
\end{tabular}

concordance was found, the reason for the discrepancy was described in further detail. Disagreement between the observers was resolved by discussion to achieve a consensus.

Infants who had one or more echocardiograms performed by a neonatologist alone (without confirmation of the diagnosis by the paediatric cardiologist) may have had a structural cardiac defect diagnosed after discharge from the neonatal unit. To pick up these false negative cases, we cross checked these infants' records against admission and outpatient attendance data from the regional cardiac centre at Royal Liverpool Children's Hospital, Alder Hey.

Statistical data were analysed using Arcus Quickstat 1.0 (Longman Software Publishing, Cambridge, UK). Groups were compared using either $\chi^{2}$ or Fisher's exact test for categorical data and Mann-Whitney $U$ test for continuous data.

\section{RESULTS}

A total of 157 echocardiograms were performed in 82 infants during the study period. The median (interquartile range, IQR) gestation and birth weight of babies scanned was 32 (27-38) weeks and 1702 (1042-3105) g respectively. Their median (IQR) age at the time of the first echocardiogram was $2(1-18)$ days. The median (IQR) number of scans/infant was $1(1-2)$ with a maximum of nine scans performed in one baby.
The most common reasons for performing an echocardiogram were an asymptomatic murmur and cardiorespiratory symptoms with or without a murmur (table 1). Although in most babies the purpose of performing echocardiography was to diagnose or exclude structural heart disease, some babies were scanned to evaluate pulmonary haemodynamics and cardiac function. Approximately half of the infants scanned (44/82, 54\% (95\% confidence interval (CI) $42 \%$ to $65 \%)$ ) had a definite structural cardiac abnormality identified on echocardiography (fig 1, table 2). In addition, 30 of the remaining 38 infants with essentially normal cardiac anatomy had evidence of either a functional cardiac abnormality (persistent pulmonary hypertension of the newborn or left ventricular dysfunction) or a trivial structural cardiac abnormality (patent foramen ovale, small PDA, or both).

Initial echocardiographic assessment prompted a specific change in clinical management in $64(78 \%, 95 \%$ CI $68 \%$ to $86 \%)$ babies. An urgent cardiology/cardiac surgery opinion was sought in 10 babies, medical treatment with routine cardiology follow up in nine babies, medical treatment without cardiology review in 16 babies, and routine cardiology follow up only in 29 babies. Echocardiography did not lead to an immediate change in clinical management in 18 infants, although a structural heart defect was excluded in five infants who had a suspected congenital heart defect on the basis of an antenatal ultrasound scan or a positive family history.

Table 2 Details of congenital structural abnormalities

\begin{tabular}{|c|c|}
\hline Abnormality & Comments \\
\hline Isolated ventricular septal defect $(n=8)$ & 6 small muscular VSDs, 2 perimembranous VSDs (2 mm and $6 \mathrm{~mm}$ ) \\
\hline Isolated atrial septal defect $(n=7)$ & Secundum ASDs, sizes ranging from 3.0 to $7.8 \mathrm{~mm}$, one in baby with trisomy 21 \\
\hline Pulmonary valve stenosis $(n=4)$ & Mild (2), moderate (1), and severe (1) \\
\hline Atrioventricular septal defect $(n=3)$ & Complete AVSDs, one in baby with trisomy 21 \\
\hline Hypoplastic left heart syndrome/hypoplastic aortic arch (n=3) & $\begin{array}{l}\text { Hypoplastic arch with critical aortic stenosis (2), hypoplastic arch with critical } \\
\text { aortic stenosis and VSD in baby with trisomy } 18 \text { (1) }\end{array}$ \\
\hline Coarctation of aorta $(n=1)$ & Coarctation of the aorta with small VSD \\
\hline Ebstein's anomaly $(n=1)$ & Antenatal diagnosis confirmed postnatally \\
\hline Transposition of the great arteries $(n=1)$ & TGA with intact ventricular septum \\
\hline Double inlet left ventricle with transposition of the great arteries $(n=1)$ & Antenatal diagnosis confirmed postnatally, VSD also present \\
\hline Complex congenital cyanotic heart defect $(n=1)$ & $\begin{array}{l}\text { Right atrial isomerism, complete AVSD, pulmonary atresia, total anomalous } \\
\text { pulmonary venous drainage }\end{array}$ \\
\hline
\end{tabular}

VSD, Ventricular sepatal defect; ASD, atrial sepatal defect; AVSD, atrioventricular septal defect; TGA, transposition of great arteries. 


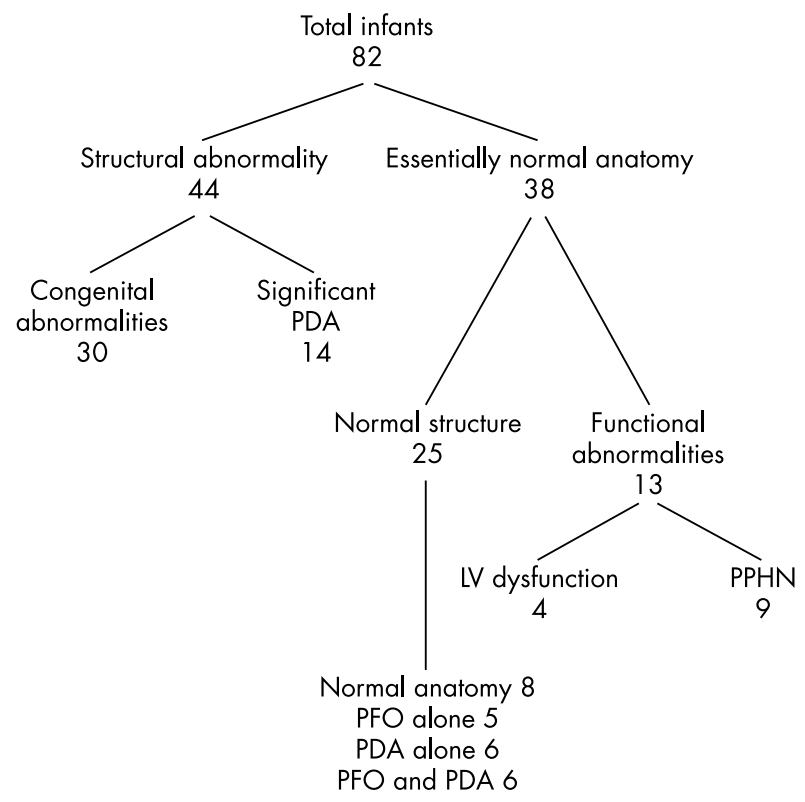

Figure 1 Echocardiographic findings. PDA, Persistent ductus arteriosus; LV, left ventricular; PPHN, persistent pulmonary hypertension of the newborn; PFO, patent foramen ovale.

Echocardiography was performed by both neonatologist and paediatric cardiologist in 38 infants. These infants who had paired examinations were broadly similar to the whole group in terms of basic details and indications for echocardiography, but were significantly more likely to have an underlying diagnosis of structural cardiac abnormality or haemodynamically significant PDA, and had significantly more scans (table 1). In 31 of the 38 (82\%, 95\% CI 66\% to 92\%) infants who had a scan performed by both neonatologist and cardiologist, there was complete concordance between the two examinations. No infants had scans that were completely different. In seven infants, there were some differences between the recorded findings of the two observers (table 3 ).

\section{DISCUSSION}

Echocardiography is often performed on our neonatal unit usually to diagnose or exclude a structural heart defect, but also to evaluate pulmonary haemodynamics and cardiac function. The yield of abnormal findings is high, with abnormalities of structure and/or function being identified in about $70 \%$ of echocardiograms. Initial echocardiographic findings directly influenced clinical management in over three quarters of babies scanned.

A recent survey of UK practice suggested that babies are often transferred out of the neonatal unit for echocardiographic assessment or receive treatment inappropriately because of the lack of availability of 24 hour on site paediatric cardiology services in most tertiary neonatal units. ${ }^{1}$ This study has again emphasised the need for ready access to echocardiographic skills on the neonatal unit. The most common reason for performing an echocardiogram was to determine whether the underlying cardiac anatomy was normal or abnormal. In addition to defining cardiac anatomy, echocardiography may also be useful in the assessment of neonatal cardiovascular physiology. In our study a considerable proportion of infants were diagnosed with a "physiological" abnormality, which led to a specific change in clinical management. Examples included identification of a haemodynamically significant PDA in a ventilated baby without a murmur, persistent pulmonary hypertension of the newborn in a baby with hypoxaemic respiratory failure, and poor left ventricular contractility in a hypotensive infant.

There was generally good agreement between the echocardiographic findings of the neonatologists and the subsequent scan performed by the cardiologist, with complete concordance in most cases. There was some disagreement in seven babies. Two infants with complex lesions were correctly identified, and, although the full details of the lesions were not defined, they were referred appropriately to a cardiac centre for further management. In two infants, a PDA was not seen on the initial scan, once by a neonatologist and once by the cardiologist. Initial failure to detect the PDA may have been because elevated pulmonary artery pressure prevented flow through the duct. Pulmonary stenosis was both overdiagnosed and underdiagnosed, and, although this did not appreciably contribute to a change in management, this experience should encourage neonatologists to evaluate the pulmonary valve particularly carefully.

In a retrospective review of referrals to a specialist paediatric cardiology centre, Ward and Purdie ${ }^{14}$ reported a misdiagnosis rate of $44 \%$ in scans performed by specialists other than trained paediatric cardiologists (mainly radiologists and adult cardiologists), with the highest proportion of errors occurring in the neonatal period. Our study is different in that we prospectively studied the performance of two neonatologists with some experience in neonatal echocardiography (but no formal training in paediatric cardiology) in an unselected infant population. In contrast with a previous suggestion that there should be a " . . restriction of individuals undertaking

Table 3 Details of discrepancies between echocardiograms performed by neonatologist and cardiologist

\begin{tabular}{lll}
\hline Neonatologist & Cardiologist & Comments \\
$\begin{array}{l}\text { Double inlet right ventricle, non-restrictive } \\
\text { VSD, possible coarctation }\end{array}$ & $\begin{array}{l}\text { Double inlet left ventricle, hypoplastic right } \\
\text { ventricle, non-restrictive VSD, TGA, normal aortic } \\
\text { arch }\end{array}$ & $\begin{array}{l}\text { Case discussed with paediatric cardiologist. Prostaglandin } \\
\text { infusion started. Infant transferred to cardiac unit for further } \\
\text { management }\end{array}$ \\
$\begin{array}{l}\text { Single ventricle and atrioventricular } \\
\text { valve, primum ASD, pulmonary atresia }\end{array}$ & $\begin{array}{l}\text { Right isomerism, complete atrioventricular septal } \\
\text { defect, pulmonary atresia, total anomalous venous } \\
\text { drainage }\end{array}$ & $\begin{array}{l}\text { Case discussed with paediatric cardiologist. Prostaglandin } \\
\text { infusion started. Infant transferred to cardiac unit for further } \\
\text { management }\end{array}$ \\
PDA not seen initially & PDA & $\begin{array}{l}\text { Possibly because of equal pulmonary artery and aortic } \\
\text { pressures initially }\end{array}$ \\
PDA & PDA not seen initially & $\begin{array}{l}\text { Possibly because of equal pulmonary artery and aortic } \\
\text { pressures initially }\end{array}$ \\
Pulmonary stenosis & No pulmonary stenosis & $\begin{array}{l}\text { Pulmonary artery initially did not appear to be opening well } \\
\text { in infant with Ebstein's anomaly of the tricuspid valve }\end{array}$ \\
$\begin{array}{l}\text { Small muscular VSD, pulmonary stenosis, Small muscular VSD, no pulmonary stenosis } \\
\text { Physiological peripheral pulmonary } \\
\text { artery stenosis }\end{array}$ & Mild pulmonary valve stenosis & $\begin{array}{l}\text { Pulmary artery initially did not appear to be opening well } \\
\text { thickened }\end{array}$ \\
\hline
\end{tabular}

VSD, Ventricular sepatal defect; ASD, atrial sepatal defect; PDA, persistent ductus arteriosus; TGA, transposition of great arteries. 
pediatric echocardiography . . ",, ${ }^{14}$ our findings support the widespread current practice in the United Kingdom of neonatologists performing echocardiograms, with close support from paediatric cardiologists. It has been proposed that telemedicine may also be useful in enabling prompt diagnosis and referral to a specialist cardiology centre, and this may be helpful especially in remote areas. ${ }^{15}$

The introduction of a formal, structured training programme and accreditation process in neonatal echocardiography (not yet available in the United Kingdom) is likely to further improve the performance of neonatologists in this area. The essential components of any training programme include opportunities for developing practical skills in echocardiography alongside specialists trained in neonatal echocardiography, reinforced by a sound understanding of the theory behind the use of ultrasound and the different ultrasound systems and modalities available. In addition to textbooks and other educational material, a number of practical courses in neonatal echocardiography are already available in the United Kingdom. ${ }^{9}{ }^{10}$ These are useful in that they provide an introduction to the subject, but cannot replace a structured training programme in neonatal echocardiography. Once acquired, maintaining echocardiographic skills will require a neonatologist to perform echocardiograms on a regular basis, with clinical sessions devoted to echocardiography in a neonatal unit able to provide a suitable caseload of patients both in terms of number and diversity of cases. We believe that this should be possible in most tertiary neonatal intensive care units in the United Kingdom. Close liaison with local colleagues in paediatric cardiology is essential to discuss echocardiographic findings, clinical diagnosis, and subsequent management. Neonatologists performing echocardiography should also audit their performance regularly to ensure that a high quality service is being delivered.

Some babies with structural heart disease may have been discharged, having been thought to have a normal heart or trivial structural abnormality from a neonatologist's echocardiogram. However, of the 24 infants who had an echocardiogram performed by a neonatologist (but where the findings were not confirmed by the paediatric cardiologist) during the neonatal admission, none was subsequently diagnosed with a structural cardiac defect that had been missed on the initial echocardiogram. We acknowledge that we cannot completely exclude the possibility that an asymptomatic baby with a structural heart defect missed on the initial echocardiogram may not yet have presented for cardiological assessment. Although it is important to recognise that there is potential for structural heart disease to be missed (a problem not confined to neonatologists), our results do not suggest that this is a common occurrence when echocardiography is performed by neonatologists in this setting. ${ }^{8}{ }^{16}$

In summary, our findings suggest that echocardiography performed on the neonatal unit has a high yield for the diagnosis of structural and functional cardiac abnormalities, often results in a change in clinical management, and is a reliable tool in the hands of neonatologists with close support from paediatric cardiologists.

\section{Authors' affiliations}

S Moss, C W Yoxall, N V Subhedar, Neonatal Intensive Care Unit, Liverpool Women's Hospital, Liverpool, UK

D J Kitchiner, Department of Paediatric Cardiology, Royal Liverpool Children's Hospital, Alder Hey, Liverpool, UK

\section{REFERENCES}

1 Moss S, Subhedar NV. Echocardiography on the neonatal unit. Arch Dis Child 2002;87:171.

2 J L Katumba-Lunyenya. Neonatal/infant echocardiography by the non-cardiologist: a personal practice, past, present, and future. Arch Dis Child Fetal Neonatal Ed 2002;86:F55-7.
3 Skinner JR. Echocardiography on the neonatal unit: a job for the neonatologist or the cardiologist? Arch Dis Child 1998;78:401-2

4 Whitehall J. Neonatologists and echocardiography. J Paediatr Child Health 2002;38:106.

5 Evans N. Echocardiographic misdiagnosis and ultrasound skills. J Paediatr Child Health 2002;38:107.

6 Kluckow M. Diagnostic accuracy of paediatric echocardiograms. J Paediatr Child Health 2002;38:108.

7 Sholler G. Echocardiography in congenital heart disease: diagnosis, misdiagnosis, and ownership. J Paediatr Child Health 2001;37:321-2.

8 Evans N. Echocardiography on neonatal intensive care units in Australia and New Zealand. J Paediatr Child Health 2000;36:169-71.

9 Skinner J, Alverson D, Hunter S (eds) In: Echocardiography for the neonatologist. Edinburgh: Churchill Livingstone, 2000.

10 Evans N, Malcolm G. Practical echocardiography for the neonatologist. Part 1. Normal 2D imaging and Doppler: an interactive multimedia CD-ROM. Sydney: Royal Prince Alfred Hospital, 2000.

11 Arlettaz R, Archer N, Wilkinson AR. Closure of the ductus arteriosus and development of pulmonary branch stenosis in babies of less than 32 weeks gestation Arch Dis Child Fetal Neonatal Ed 2001:85:F197-200.

12 Kinsella JP, Abman SH. Recent developments in the pathophysiology and treatment of persistent pulmonary hypertension of the newborn. $J$ Pediatr 1995; 126:853-64.

13 Evans N, Kluckow M. Early determinants of right and left ventricular output in ventilated preterm infants. Arch Dis Child Fetal Neonatal Ed 1996;74: F88-94.

14 Ward CJ, Purdie J. Diagnostic accuracy of paediatric echocardiograms interpreted by individuals other than paediatric cardiologists. J Paediatr Child Health 2001;37:331-6.

15 Randolph GR, Hagler DJ, Khandheria BK, et al. Remote telemedical interpretation of neonatal echocardiograms: impact on clinical management in a primary care setting. J Am Coll Cardiol 1999;34:241-5.

16 Whitehall J. Echocardiography by a neonatologist. Arch Dis Child 1999;80:579.

\section{COMMENTARY}

Echocardiography is the standard investigation for the diagnosis or exclusion of congenital heart disease and for assessment of cardiovascular function. Ultrasound machines are available on most neonatal units and are widely used by neonatologists for cranial, renal, and abdominal ultrasound examination. There is no reason why neonatologists should not also perform echocardiography, although, so far, relatively few have acquired this skill.

Echocardiography is used in neonatal units for the diagnosis and assessment of patent ductus arteriosus, for the assessment of myocardial function, pulmonary hypertension, and haemodynamic status, and for the recognition or exclusion of suspected congenital heart disease. ${ }^{1}$ When echocardiography is necessary, it is usually needed soon. There is no universal model for adequate provision of such a service in all units. Paediatric cardiologists are unable to provide a complete service in most units, and in the United Kingdom there are too few paediatric cardiologists working in only a few large centres. The current severe staffing shortage in the United Kingdom and the possible future reduction in the number of centres mean that this service will not be developed by paediatric cardiology in the near future. The transport of a baby to the paediatric cardiology centre may be the best option when the likelihood of significant congenital heart disease is high but it is not the best option for the majority. ${ }^{2}$ The use of an adult echocardiography service is known to be unreliable and is not to be recommended. ${ }^{3}$ The best option is for neonatologists to provide the echocardiography service, either by acquiring and maintaining expertise themselves or by using telemedicine for online expert support. ${ }^{4}$

How best should neonatologists train in and practice echocardiography? Those who perform echocardiography at present have mainly arranged their own training as no formal system or guidelines exist in the United Kingdom. ${ }^{5}$ Training involves both formal teaching from attendance at courses or published CDS or textbooks and continuing practice. ${ }^{67}$ Safe practice requires continuing performance of echocardiography and recognition of one's own abilities and limitations. 
The structural cardiovascular malformations that cause most diagnostic difficulty are total anomalous pulmonary venous connection and coarctation of the aorta, and in population terms both of these are rare. Confident and competent exclusion of something one has never seen is very difficult, so regular attendance at a paediatric cardiology centre and exposure to significant numbers of abnormal echocardiograms is also important. Sometimes the hardest thing is to recognise normality with confidence. Moss et al have reported the findings of a small audit of practice of echocardiography in a neonatal unit. Overall agreement between neonatal and paediatric cardiology scans was fairly good, although only eight echocardiograms were normal. The fact that no significant errors occurred in a small number does not guarantee that this is safe practice, ${ }^{8}$ and the experience cannot necessarily be extrapolated to other units.

Any recognition or suspicion of congenital heart disease should prompt referral to a paediatric cardiologist. Some authors have been critical of attempts by neonatologists to perform echocardiograms. ${ }^{910}$ However, the neonatologist's main use for the technique is haemodynamic assessment rather than precise diagnosis of structural defects. ${ }^{11}$

Neonatologists should develop and practice skills in cardiac ultrasound as they do with other types of ultrasound. They should also develop and adopt guidelines for good training and safe practice, audit their performance, recognise both their expertise and their limitations, and develop their expertise by close contact with a local paediatric cardiology unit.

\section{Wren}

Freeman Hospital, Newcastle upon Tyne NE7 7DN, UK; christopher.wren@tfh.nuth.northy.nhs.uk

\section{REFERENCES}

1 Kluckow M. Diagnostic accuracy of paediatric echocardiograms J Paediatr Child Health 2002;38: 108.

2 Evans N. Echocardiography on neonatal intensive care units in Australia and New Zealand. J Paediatr Child Health 2000;36:169-71.

3 Stanger $\mathbf{P}$, Silverman NH, Foster E. Diagnostic accuracy of pediatric echocardiograms performed in adult laboratories. Am J Cardiol 1999;83:908-14.

4 Casey FA. Telemedicine in paediatric cardiology. Arch Dis Child 1999;80:497-9.

5 Katumba-Lunyenya JL. Neonatal/infant echocardiography by the non-cardiologist: a personal practice, past, present, and future. Arch Dis Child Fetal Neonatal Ed 2002;86:F55-7.

6 Evans N, Malcolm G. Practical echocardiography for the neonatologist. $C D$ ROM parts 1 \& 2. Sydney: Royal Prince Alfred Hospital 2000 \& 2002. Available from www.cs.nsw.gov.au/rpa/neonatal/default.htm

7 Skinner J, Alverson D, Hunter S. Echocardiography for the neonataologist. Edinburgh: Chuchill Livingstone, 200.

8 Hanley JA, Lippman-Hand A. If nothing goes wrong, is everything all right? JAMA 1983;249:1743-5.

9 Ward CJ, Purdie J. Diagnostic accuracy of paediatric echocardiograms interpreted by individuals other than paediatric cardiologists. J Paediatr Child Health 2001;37:331-6.

10 Scholler G. Echocardiography in congenital heart disease: diagnosis, misdiagnosis, and ownership. J Paediatr Child Health 2001;37:321-3.

11 Evans N. Echocardiographic misdiagnosis and ultrasound skills. J Paediatr Child Health 2002;38:107-8. 